\title{
Sifat-sifat Operasi Perkalian Modular pada Graf Fuzzy Lengkap, Graf Fuzzy Efektif dan Graf Fuzzy Komplemen
}

\author{
Triyani, Niken Larasati, Ari Wardayani \\ Jurusan Matematika, Fakultas MIPA, Universitas Jenderal Soedirman. \\ trianisr@yahoo.com
}

\begin{abstract}
Abstrak
Penelitian ini bertujuan menyelidiki sifat-sifat operasi perkalian modular pada graf fuzzy yang diperkenalkan oleh Dogra [2]. Sifat yang diselidiki adalah perkalian modular pada graf fuzzy lengkap, graf fuzzy efektif dan graf fuzzy komplemen. Metode yang digunakan pada penelitian ini adalah metode penelitian teoritik. Hasil penelitian menunjukkan bahwa perkalian modular dari dua graf fuzzy lengkap bukan merupakan graf fuzzy lengkap, jika ke dua graf fuzzy efektif, maka perkalian modular dari dua graf fuzzy komplemennya sama dengan perkalian modular dari dua graf fuzzy efektif tersebut dan perkalian modular dari dua graf fuzzy $G_{1} \odot G_{2}$ dan $G_{2} \odot G_{1}$ saling isomorfis.
\end{abstract}

Kata kunci: graf fuzzy, perkalian modular, graf fuzzy lengkap, graf fuzzy efektif, graf fuzzy komplemen.

\begin{abstract}
The objective of this study is to investigate the characteristics of modular product on fuzzy graph which was introduced by Dogra [2]. This theoretical study focused on characteristics of modular product to complete fuzzy graph, effective fuzzy graph, and complement fuzzy graph. The result shows that modular product of two complete fuzzy graphs was not a complete fuzzy graph, and if the two fuzzy graphs are effective, the modular product of the complements equals the modular product of two effective fuzzy graphs and $G_{1} \odot G_{2} \cong G_{2} \odot G_{1}$.

Keywords :fuzzy graph, modular product, complete fuzzy graph, effective fuzzy graph, complement fuzzy graph.
\end{abstract}

\section{Pendahuluan}

Graf merupakan suatu model matematika paling sederhana yang dapat merepresentasikan hubungan antar objek dengan titik mewakili objek tertentu dan sisi yang menghubungkan antara dua objek merepresentasikan hubungan antara dua objek tersebut. Banyak permasalahan riil yang dapat direpresentasikan ke dalam graf, seperti masalah jaringan sosial, penjadwalan, pewarnaan peta dan lain-lain. Dalam masalah jaringan sosial, titik dapat merepresentasikan akun/pengguna jaringan, sedangkan hubungan antar akun direpresentasikan dengan sisi. Jika baik buruknya hubungan diukur dengan sering tidaknya ke dua pengguna melakukan komunikasi, maka dalam mendiskripsikan hubungan ini sangat dibutuhkan suatu desain model graf fuzzy.

2000 Mathematics Subject Classification: 05C72

Received: 2018-04-29, accepted: 2018-05-02. 
Graf fuzzy telah diprakarsai oleh Rosenfeld pada tahun 1975. Graf fuzzy merupakan perluasan dari graf klasik yang dikembangkan berdasarkan konsep pada logika fuzzy dan relasi fuzzy dalam teori himpunan fuzzy yang dikemukakan oleh Zadeh [6]. Jika pada graf klasik setiap elemen-elemennya (titik dan sisi) mempunyai nilai keanggotaan satu atau nol, maka pada graf fuzzy, setiap titik dan sisinya memiliki nilai keanggotaan yang terletak pada interval tutup $[0,1]$. Nilai keanggotaan setiap elemen ini menyatakan derajat keanggotaan elemen tersebut dalam graf fuzzy.

Sejak diperkenalkan graf fuzzy ini, para peneliti mulai menggeneralisasi dan mengembangkan beberapa kajian dalam graf klasik ke dalam graf fuzzy baik secara teori maupun aplikasi. Secara aplikasi graf fuzzy dapat dikatakan sebagai suatu topik yang dapat diterapkan dalam ilmu dan teknologi modern khususya dalam bidang teori informasi, jaringan syaraf, analisis cluster, diagnosa medis, dan teori kontrol [1]. Dey, et. al [1], telah mengaplikasikan graf fuzzy untuk menyelesaikan masalah traffic light dan Swaminathan [3], telah menerapkan graf fuzzy ke dalam masalah pengalokasian pekerjaan.

Secara teori, Yeh dan Bang dalam Zadeh [6] juga telah memperkenalkan beberapa konsep yang berhubungan dengan graf fuzzy seperti konsep keterhubungan fuzzy. Setelah konsepkonsep dalam graf fuzzy diperkenalkan, hasil-hasil teoritis yang lebih mendalam tentang graf fuzzy banyak diberikan, diantaranya oleh Moderson dan Peng [4] memperkenalkan konsep operasi-operasi pada graf fuzzy antara lain operasi gabungan, join, hasil kali kartesian, dan komposisi pada dua graf fuzzy. Selanjutnya Dogra [2] telah mendefinisikan operasi perkalian modular pada graf fuzzy dan menyelidiki sifat operasi modular pada dua graf fuzzy sembarang serta graf fuzzy efektif. Dalam artikelnya, Dogra [2] belum mengkaji sifat-sifat operasi perkalian modular pada graf fuzzy yang berkaitan dengan graf fuzzy lengkap, graf fuzzy komplemen, dan graf fuzzy isomorfis. Oleh karena itu berdasarkan uraian tersebut, tujuan dari penulisan artikel ini adalah menyelidiki sifat operasi perkalian modular pada dua graf fuzzy lengkap, operasi perkalian modular pada komplemen dari dua graf fuzzy efektif dan menunjukkan bahwa perkalian modular graf fuzzy $G_{1}$ dan $G_{2}$ isomorfik dengan perkalian modular graf fuzzy $G_{2}$ dan $G_{1}$.

\section{Metode Penelitian}

Metode penelitian yang digunakan dalam penelitian ini adalah studi literatur mengenai operasi perkalian modular pada graf fuzzy yang didefinisikan oleh Dogra [2]. Selanjutnya perkalian modular ini dikenakan pada dua graf fuzzy lengkap, dan komplemen dari graf fuzzy efektif. Hasil operasi perkalian modular ini selanjutnya dituangkan sebagai sifat-sifat operasi perkalian modular yang ditulis dalam bentuk bukti secara sistematis.

\section{Hasil DAN Pembahasan}

Sebelum menguraikan beberapa sifat-sifat operasi perkalian modular yang telah diperoleh, berikut diberikan teori dasar dan definisi-definisi yang berkaitan dengan hasil tersebut. Definisi yang terdapat dalam artikel ini diambil dari Dogra [2], Mordeson [4] dan Sunita [5].

Definisi 3.1. Misal $V$ adalah himpunan tak kosong dan berhingga. Suatu graf fuzzy $G$ dinotasikan dengan $G=(\sigma, \mu)$ adalah pasangan fungsi $\sigma$ yang menyatakan himpunan fuzzy dari $V$ dan $\mu$ merupakan relasi fuzzy simetris pada $\sigma$ sedemikian sehingga:

(1) $\sigma: V \rightarrow[0,1]$

(2) $\mu: V \times V \rightarrow[0,1]$ yang memenuhi $\mu\left(v_{i}, v_{j}\right) \leq \min \left\{\sigma\left(v_{i}\right), \sigma\left(v_{j}\right)\right\}$, untuk setiap $v_{i}, v_{j} \in V$

Selanjutnya, $\sigma$ disebut sebagai himpunan titik fuzzy dan $\mu$ disebut sebagai himpunan sisi fuzzy. Notasi $\sigma\left(v_{i}\right)$ pada graf fuzzy menyatakan derajat keanggotaan dari titik $v_{i}$ dan $\mu\left(v_{i}, v_{j}\right)$ menyatakan derajat keanggotaan dari sisi $\left(v_{i}, v_{j}\right)$ Graf fuzzy yang dibahas dalam artikel ini adalah graf fuzzy sederhana, sehingga berlaku $\mu\left(v_{i}, v_{j}\right)=0$ untuk setiap $v_{i}, v_{j} \in V$.

Graf fuzzy dapat direpresentasikan ke dalam sebuah gambar sebagaimana graf klasik dengan titik-titik dan sisi-sisi yang dilengkapi dengan derajat keanggotaannya. Untuk setiap 
$v_{i} \in V$ jika $\sigma\left(v_{i}\right)=0$ atau $\mu\left(v_{i}, v_{j}\right)=0$, maka titik fuzzy $v_{i}$ atau sisi fuzzy $\left(v_{i}, v_{j}\right)$ tidak digambarkan. Gambar 1 merupakan contoh graf fuzzy $G=(\sigma, \mu)$ dengan himpunan titik fuzzy $\sigma=\left\{\left(v_{1} \mid 0,4\right),\left(v_{2} \mid 0,6\right),\left(v_{3} \mid 0,8\right),\left(v_{4} \mid 1\right)\right\}$ dan himpunan sisi fuzzy $\mu=\left\{\left(v_{1} v_{3} \mid 0,2\right),\left(v_{1} v_{4} \mid 0,4\right),\left(v_{2} v_{3} \mid 0,4\right),\left(v_{2} v_{4} \mid 0,6\right),\left(v_{3} v_{4} \mid 0,8\right)\right\}$.

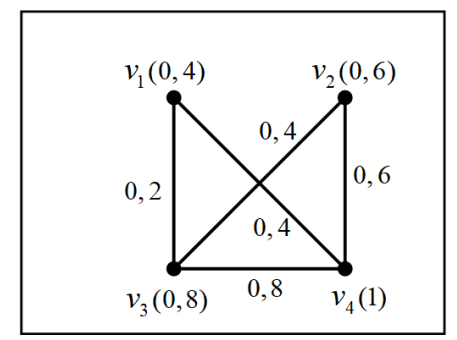

\section{Gambar 1. Graf fuzzy $\mathrm{G}=(\sigma, \mu)$}

Definisi 3.2. Graf dasar dari graf fuzzy. Graf dasar dari graf fuzzy $G=(\sigma, \mu)$ dinotasikan dengan $G^{*}=\left(\sigma^{*}, \mu^{*}\right)$ dengan $\sigma^{*}$ merujuk pada himpunan tak kosong $V$ dan $\mu^{*} \neq E \subseteq V \times V$ adalah graf dengan $\sigma^{*}=\{v \in V \mid \sigma(v)>0\}$ dan $\mu^{*}=\left\{v_{i} v_{j} \in E \mid \mu\left(v_{i} v_{j}\right)>0\right\}$.

Berdasarkan definisi 3.2. ini, graf dasar dari graf fuzzy adalah graf klasik $G=(V, E)$.

Definisi 3.3. Perkalian modular pada dua graf fuzzy. Misalkan $G_{1}=\left(\sigma_{1}, \mu_{1}\right)$ dan $G_{2}=$ $\left(\sigma_{2}, \mu_{2}\right)$ adalah dua graf fuzzy dengan masing-masing graf dasar $G_{1}^{*}=\left(V_{1}, E_{1}\right), G_{2}^{*}=\left(V_{2}, E_{2}\right)$ dan $V_{1} \cap V_{2}=\varnothing$. Jika perkalian modular dari $G_{1}^{*}$ dan $G_{2}^{*}$ adalah $G^{*}=G_{1}^{*} \odot G_{2}^{*}=(V, E)$ dengan himpunan titik dan sisinya didefinisikan sebagai :

(1) $V=V_{1} \odot V_{2}=V_{1} \times V_{2}=\left\{(u, v) \mid u \in V_{1}, v \in V_{2}\right\}$

(2) $E=E_{1} \odot E_{2}=\left\{\left(\left(u_{i}, v_{j}\right)\left(u_{k}, v_{l}\right)\right) \mid u_{i} u_{k} \in E_{1}, v_{j} v_{l} \in E_{2}\right.$ atau $\left.u_{i} u_{k} \notin E_{1}, v_{j} v_{l} \notin E_{2}\right\}$

dimana $i, k=1,2, \ldots\left|V_{1}\right|$ dan $j, l=1,2, \ldots,\left|V_{2}\right|$, maka perkalian modular dari dua graf fuzzy $G_{1}=\left(\sigma_{1}, \mu_{1}\right)$ dan $G_{2}=\left(\sigma_{2}, \mu_{2}\right)$ dinotasikan dengan $G=G_{1} \odot G_{2}=\left(\sigma_{1} \odot \sigma_{2}, \mu_{1} \odot \mu_{2}\right)$ adalah pasangan fungsi yang didefinisikan oleh:

(1) $\left(\sigma_{1} \odot \sigma_{2}\right)(u, v)=\sigma_{1}(u) \wedge \sigma_{2}(v)$, dimana $u \in V_{1}$ dan $v \in V_{2}$

(2) $\left(\mu_{1} \odot \mu_{2}\right)\left(\left(u_{i}, v_{j}\right)\left(u_{k}, v_{l}\right)\right)=\left\{\begin{array}{l}\mu_{1}\left(u_{i} u_{k}\right) \wedge \mu_{2}\left(v_{j} v_{l}\right) \quad u_{i} u_{k} \in E_{1} \text { dan } v_{j} v_{l} \in E_{2} \\ \sigma_{1}\left(u_{i}\right) \wedge \sigma_{1}\left(u_{j}\right) \wedge \sigma_{2}\left(v_{k}\right) \wedge \sigma_{2}\left(v_{l}\right), u_{i} u_{k} \notin E_{1} \text { dan } v_{j} v_{l} \notin E_{2}\end{array}\right.$

Gambar 2. merupakan contoh operasi perkalian modular pada dua graf fuzzy $G_{1}=$ $\left(\sigma_{1}, \mu_{1}\right)$ dan $G_{2}=\left(\sigma_{2}, \mu_{2}\right)$.

Definisi 3.4. Graf fuzzy efektif. Suatu graf fuzzy $G=(\sigma, \mu)$ adalah graf fuzzy efektif jika memenuhi $\mu\left(v_{i}, v_{j}\right)=\min \left\{\sigma\left(v_{i}\right), \sigma\left(v_{j}\right)\right\}$ untuk setiap $\left(v_{i}, v_{j}\right) \in E$ dimana $E \subseteq V \times V$.

Definisi 3.5. Graf fuzzy lengkap. Suatu graf fuzzy $G=(\sigma, \mu)$ adalah graf fuzzy lengkap jika memenuhi $\mu\left(v_{i}, v_{j}\right)=\min \left\{\sigma\left(v_{i}\right), \sigma\left(v_{j}\right)\right\}$ untuk setiap $\left(v_{i}, v_{j}\right) \in V$.

Berdasarkan definisi 3.5, setiap dua titik fuzzy pada graf fuzzy lengkap terhubung oleh sebuah sisi fuzzy, sedangkan pada graf fuzzy efektif tidak setiap dua titik fuzzynya terhubung oleh sebuah sisi. Sehingga dapat disimpulkan bahwa graf fuzzy lengkap merupakan graf fuzzy efektif tetapi tidak sebaliknya. 


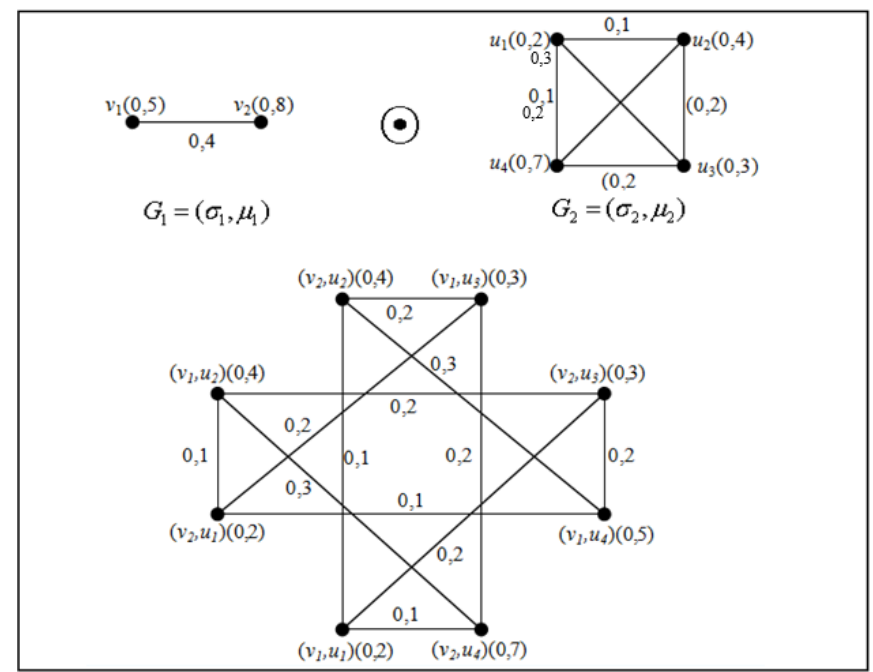

GAmbar 2. $G_{1} \odot G_{2}=\left(\sigma_{1} \odot \sigma_{2}, \mu_{1} \odot \mu_{2}\right)$

Komplemen pada graf fuzzy pertama kali didefinisikan oleh Mordeson [5], yang kemudian disempurnakan oleh Sunita [5]. Berikut definisi komplemen dari graf fuzzy yang diambil dari Sunita [5].

Definisi 3.6. Komplemen dari graf fuzzy. Misal $V$ adalah himpunan tak kosong. Komplemen dari graf fuzzy $G=(\sigma, \mu)$ adalah graf fuzzy $G^{c}=\left(\sigma^{c}, \mu^{c}\right)$ dimana $\sigma^{c}=\sigma$ dan $\mu^{c}\left(v_{i}, v_{j}\right)=\min \left\{\sigma\left(v_{i}\right), \sigma\left(v_{j}\right)\right\}-\mu\left(v_{i}, v_{j}\right)$ untuk setiap $v_{i}, v_{j} \in V$.

Selanjutnya komplemen dari graf fuzzy disebut graf fuzzy komplemen. Berdasarkan definisi 3.6, berlaku $\left(G^{c}\right)^{c}=G$.

Definisi 3.7. Graf fuzzy Isomorfik. Misal $G_{1}=\left(\sigma_{1}, \mu_{1}\right)$ dan $G_{2}=\left(\sigma_{2}, \mu_{2}\right)$ adalah dua graf fuzzy dengan himpunan titik $V_{1}, V_{2}$. Jika terdapat pemetaan bijektif $f: V_{1} \rightarrow V_{2}$ yang memenuhi :

(1) $\sigma_{1}(u)=\sigma_{2}(f(u)) \forall u \in V_{1}$

(2) $\mu_{1}(u, v)=\mu_{2}(f(u), f(v)) \forall u, v \in V_{1}$

maka dikatakan $G_{1}=\left(\sigma_{1}, \mu_{1}\right)$ dan $G_{2}=\left(\sigma_{2}, \mu_{2}\right)$ saling isomorfis, dan dinotasikan dengan $G_{1} \cong G_{2}$.

Berikut diberikan dua sifat operasi perkalian modular pada graf fuzzy yang telah diperoleh oleh Dogra [2].

Teorema 3.1.Perkalian modular dari dua graf fuzzy adalah graf fuzzy.

Bukti. Misalkan diberikan dua himpunan tak kosong $V_{1}, V_{2}$ dengan $V_{1} \cap V_{2}=\varnothing$, dan dua graf fuzzy $G_{1}=\left(\sigma_{1}, \mu_{1}\right), G_{2}=\left(\sigma_{2}, \mu_{2}\right)$. Untuk membuktikann hasil operasi perkalian modular dua graf fuzzy $G_{1}$ dan $G_{2}$ juga merupakan graf fuzzy, maka harus dibuktikan

(1) $\sigma_{1} \odot \sigma_{2}: V_{1} \times V_{2} \rightarrow[0,1]$

(2) $\mu_{1} \odot \mu_{2}: E \rightarrow[0,1]$ dengan $E=\left\{\left(\left(u_{i}, v_{j}\right)\left(u_{k}, v_{l}\right)\right) \mid u_{i} u_{k} \in E_{1}, v_{j} v_{l} \in E_{2}\right.$ atau $u_{i} u_{k} \notin$ $\left.E_{1}, v_{j} v_{l} \notin E_{2}\right\}$

yang memenuhi $\left(\mu_{1} \odot \mu_{2}\right)\left(\left(u_{i}, v_{j}\right)\left(u_{k}, v_{l}\right)\right) \leq \min \left\{\left(\sigma_{1} \odot \sigma_{2}\right)\left(u_{i}, v_{j}\right),\left(\sigma_{1} \odot \sigma_{2}\right)\left(u_{k}, v_{l}\right)\right\}$, untuk setiap $\left(u_{i}, v_{j}\right),\left(u_{k}, v_{l}\right) \in V$.

Untuk menunjukkan (1), diambil sembarang $(u, v) \in V_{1} \times V_{2}$. Berdasarkan definisi 3.3, maka $\left(\sigma_{1} \odot \sigma_{2}\right)(u, v)=\sigma_{1}(u) \wedge \sigma_{2}(v)=\min \left\{\sigma_{1}(u), \sigma_{2}(v)\right\}$

Karena $G_{1}$ dan $G_{2}$ adalah graf fuzzy, maka $\sigma_{1}(u) \in[0,1]$ dan $\sigma_{2}(v) \in[0,1]$, Akibatnya $\left(\sigma_{1} \odot\right.$ 
$\left.\sigma_{2}\right)(u, v) \in[0,1]$. Dengan kata lain $\sigma_{1} \odot \sigma_{2}: V_{1} \times V_{2} \rightarrow[0,1]$.

Untuk menunjukan (2), diambil sembarang $\left(u_{i}, v_{j}\right)\left(u_{k}, v_{l}\right) \in E$ dengan $u_{i}, u_{k} \in V_{1}, v_{j}, v_{l} \in V_{2}$.

\section{Kasus 1.}

$u_{i} u_{k} \in E_{1}$ dan $v_{j} v_{l} \in E_{2}$. Berdasarkan definisi 3.3, diperoleh :

$$
\begin{aligned}
\left(\mu_{1} \odot \mu_{2}\right)\left(\left(u_{i}, v_{j}\right)\left(u_{k}, v_{l}\right)\right) & =\mu_{1}\left(u_{i} u_{k}\right) \wedge \mu_{2}\left(v_{j} v_{l}\right) \\
& \leq \sigma_{1}\left(u_{i}\right) \wedge \sigma_{1}\left(u_{k}\right) \wedge \sigma_{2}\left(v_{j}\right) \wedge \sigma_{2}\left(v_{l}\right) \quad \text { (definisi3.1) } \\
& =\sigma_{1}\left(u_{i}\right) \wedge \sigma_{2}\left(v_{j}\right) \wedge \sigma_{1}\left(u_{k}\right) \wedge \sigma_{2}\left(v_{l}\right) \\
& =\left(\sigma_{1} \odot \sigma_{2}\right)\left(u_{i}, v_{j}\right) \wedge\left(\sigma_{1} \odot \sigma_{2}\right)\left(u_{k}, v_{l}\right) \\
& =\min \left\{\left(\sigma_{1} \odot \sigma_{2}\right)\left(u_{i}, v_{j}\right),\left(\sigma_{1} \odot \sigma_{2}\right)\left(u_{k}, v_{l}\right)\right\}
\end{aligned}
$$

Kasus 2.

$u_{i} u_{k} \notin E_{1}$ dan $v_{j} v_{l} \notin E_{2}$. Berdasarkan definisi 3.3, diperoleh :

$$
\begin{aligned}
\left(\mu_{1} \odot \mu_{2}\right)\left(\left(u_{i}, v_{j}\right)\left(u_{k}, v_{l}\right)\right) & =\sigma_{1}\left(u_{i}\right) \wedge \sigma_{1}\left(u_{k}\right) \wedge \sigma_{2}\left(v_{j}\right) \wedge \sigma_{2}\left(v_{l}\right) \\
& =\sigma_{1}\left(u_{i}\right) \wedge \sigma_{2}\left(v_{j}\right) \wedge \sigma_{1}\left(u_{k}\right) \wedge \sigma_{2}\left(v_{l}\right) \\
& =\left(\sigma_{1} \odot \sigma_{2}\right)\left(u_{i}, v_{j}\right) \wedge\left(\sigma_{1} \odot \sigma_{2}\right)\left(u_{k}, v_{l}\right) \\
& =\min \left\{\left(\sigma_{1} \odot \sigma_{2}\right)\left(u_{i}, v_{j}\right),\left(\sigma_{1} \odot \sigma_{2}\right)\left(u_{k}, v_{l}\right)\right\}
\end{aligned}
$$

Berdasarkan kasus 1 dan 2, terbukti bahwa

$$
\left(\mu_{1} \odot \mu_{2}\right)\left(\left(u_{i}, v_{j}\right)\left(u_{k}, v_{l}\right)\right) \leq \min \left\{\left(\sigma_{1} \odot \sigma_{2}\right)\left(u_{i}, v_{j}\right),\left(\sigma_{1} \odot \sigma_{2}\right)\left(u_{k}, v_{l}\right)\right\}
$$

Hal ini berarti $\left(\mu_{1} \odot \mu_{2}\right)\left(\left(u_{i}, v_{j}\right)\left(u_{k}, v_{l}\right)\right) \in[0,1]$. Dengan kata lain $\mu_{1} \odot \mu_{2}: E \rightarrow[0,1]$. Berdasarkan bukti (1) dan (2), maka hasil operasi perkalian modular dua graf fuzzy $G_{1}$ dan $G_{2}$ juga merupakan graf fuzzy.

Teorema 3.2.Perkalian modular dari dua graf fuzzy efektif adalah graf fuzzy efektif.

Bukti. Berdasarkan definisi 3.4, akan dibuktikan

(1) $\sigma_{1} \odot \sigma_{2}: V_{1} \times V_{2} \rightarrow[0,1]$

(2) $\left(\mu_{1} \odot \mu_{2}\right)\left(\left(u_{i}, v_{j}\right)\left(u_{k}, v_{l}\right)\right)=\min \left\{\left(\sigma_{1} \odot \sigma_{2}\right)\left(u_{i}, v_{j}\right),\left(\sigma_{1} \odot \sigma_{2}\right)\left(u_{k}, v_{l}\right)\right\}$, untuk setiap $\left(u_{i}, v_{j}\right),\left(u_{k}, v_{l}\right) \in V$.

Untuk menunjukkan (1), diambil sembarang $(u, v) \in V_{1} \times V_{2}$. Berdasarkan definisi 3.3, maka $\left(\sigma_{1} \odot \sigma_{2}\right)(u, v)=\sigma_{1}(u) \wedge \sigma_{2}(v)=\min \left\{\sigma_{1}(u), \sigma_{2}(v)\right\}$.

Karena $G_{1}$ dan $G_{2}$ adalah graf fuzzy, maka $\sigma_{1}(u) \in[0,1]$ dan $\sigma_{2}(v) \in[0,1]$. Akibatnya $\left(\sigma_{1} \odot\right.$ $\left.\sigma_{2}\right)(u, v) \in[0,1]$. Dengan kata lain $\sigma_{1} \odot \sigma_{2}: V_{1} \times V_{2} \rightarrow[0,1]$.

Untuk membuktikan (2), diambil sembarang $\left(u_{i}, v_{j}\right)\left(u_{k}, v_{l}\right) \in E$, dengan $u_{i}, u_{k} \in V_{1}, v_{j}, v_{l} \in V_{2}$.

\section{Kasus 1.}

$u_{i} u_{k} \in E_{1}$ dan $v_{j} v_{l} \in E_{2}$. Berdasarkan definisi 3.3, diperoleh :

$$
\begin{aligned}
\left(\mu_{1} \mu_{2}\right)\left(\left(u_{i}, v_{j}\right)\left(u_{k}, v_{l}\right)\right) & =\mu_{1}\left(u_{i} u_{k}\right) \wedge \mu_{2}\left(v_{j} v_{l}\right) \\
& =\sigma_{1}\left(u_{i}\right) \wedge \sigma_{1}\left(u_{k}\right) \wedge \sigma_{2}\left(v_{j}\right) \wedge \sigma_{2}\left(v_{l}\right) \\
& =\sigma_{1}\left(u_{i}\right) \wedge \sigma_{2}\left(v_{j}\right) \wedge \sigma_{1}\left(u_{k}\right) \wedge \sigma_{2}\left(v_{l}\right) \\
& =\left(\sigma_{1} \odot \sigma_{2}\right)\left(u_{i}, v_{j}\right) \wedge\left(\sigma_{1} \odot \sigma_{2}\right)\left(u_{k}, v_{l}\right) \\
& =\min \left\{\left(\sigma_{1} \odot \sigma_{2}\right)\left(u_{i}, v_{j}\right),\left(\sigma_{1} \odot \sigma_{2}\right)\left(u_{k}, v_{l}\right)\right\}
\end{aligned}
$$

\section{Kasus 2.}

$u_{i} u_{k} \notin E_{1}$ dan $v_{j} v_{l} \notin E_{2}$.

$$
\begin{aligned}
\left(\mu_{1} \odot \mu_{2}\right)\left(\left(u_{i}, v_{j}\right)\left(u_{k}, v_{l}\right)\right) & =\sigma_{1}\left(u_{i}\right) \wedge \sigma_{1}\left(u_{k}\right) \wedge \sigma_{2}\left(v_{j}\right) \wedge \sigma_{2}\left(v_{l}\right) \\
& =\left(\sigma_{1} \odot \sigma_{2}\right)\left(u_{i}, v_{j}\right) \wedge\left(\sigma_{1} \odot \sigma_{2}\right)\left(u_{k}, v_{l}\right) \\
& =\min \left\{\left(\sigma_{1} \odot \sigma_{2}\right)\left(u_{i}, v_{j}\right),\left(\sigma_{1} \odot \sigma_{2}\right)\left(u_{k}, v_{l}\right)\right\}
\end{aligned}
$$

Berdasarkan kasus 1 dan 2, terbukti bahwa

$$
\left(\mu_{1} \odot \mu_{2}\right)\left(\left(u_{i}, v_{j}\right)\left(u_{k}, v_{l}\right)\right)=\min \left\{\left(\sigma_{1} \odot \sigma_{2}\right)\left(u_{i}, v_{j}\right),\left(\sigma_{1} \odot \sigma_{2}\right)\left(u_{k}, v_{l}\right)\right\}
$$

Berdasarkan bukti (1) dan (2), maka terbukti hasil operasi perkalian modular dua graf fuzzy efektif merupakan graf fuzzy efektif.

Berikut beberapa sifat operasi perkalian modular pada dua graf fuzzy yang di kembangkan oleh penulis dan dituangkan sebagai Teorema 3.3., Teorema 3.4., dan Teorema 3.5. 
Teorema 3.3. Perkalian modular dari dua graf fuzzy lengkap bukan merupakan graf fuzzy lengkap.

Bukti. Misal diberikan dua graf fuzzy lengkap $G_{1}=\left(\sigma_{1}, \mu_{1}\right)$ dan $G_{2}=\left(\sigma_{2}, \mu_{2}\right)$. Berdasarkan definisi 3.3, derajat keanggotaan sisi dari graf fuzzy hasil perkalian modular graf fuzzy $G_{1}$ dan $G_{2}$ adalah

$$
\left(\mu_{1} \odot \mu_{2}\right)\left(\left(u_{i}, v_{j}\right)\left(u_{k}, v_{l}\right)\right)= \begin{cases}\mu_{1}\left(u_{i} u_{k}\right) \wedge \mu_{2}\left(v_{j} v_{l}\right), & u_{i} u_{k} \in E_{1} \text { dan } v_{j} v_{l} \in E_{2} \\ \sigma_{1}\left(u_{i}\right) \wedge \sigma_{1}\left(u_{j}\right) \wedge \sigma_{2}\left(v_{k}\right) \wedge \sigma_{2}\left(v_{l}\right), u_{i} u_{k} \notin E_{1} \text { dan } v_{j} v_{l} \notin E_{2}\end{cases}
$$

Akibatnya, $\left(\mu_{1} \odot \mu_{2}\right)\left(\left(u_{i}, v_{j}\right)\left(u_{k}, v_{l}\right)\right)=0$, untuk $i=k$ atau $j=l$. Sehingga tidak setiap dua titik di $G_{1} \odot G_{2}$ terhubung oleh sisi. Berdasarkan Definisi 3.5., hasil operasi modular $G_{1}$ dan $G_{2}$ bukan graf fuzzy lengkap.

Gambar 3 berikut, merupakan contoh yang menjelaskan sifat 3.3. Graf fuzzy pada Gambar 3(c) merupakan graf fuzzy hasil perkalian modular dari dua graf fuzzy lengkap (Gambar 3(a) dan Gambar 3(b)). Graf fuzzy pada Gambar 3(c), bukan graf fuzzy lengkap.

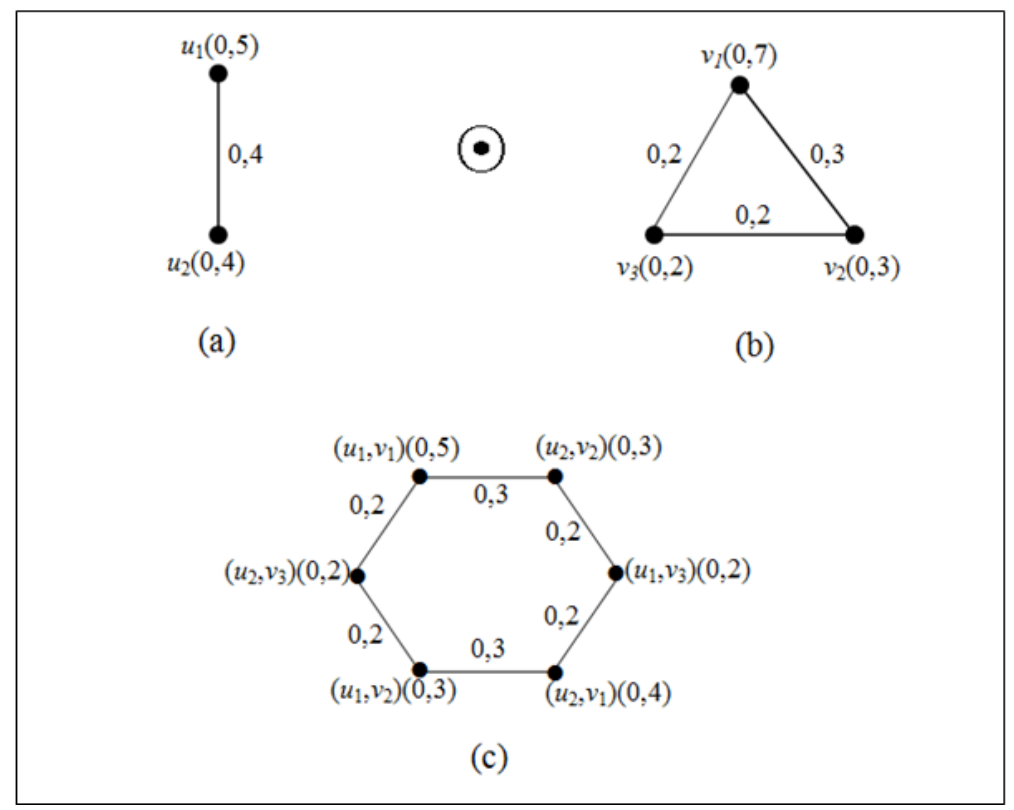

Gambar 3. (a) Contoh Graf fuzzy lengkap $G_{1}$, (b) Contoh Graf fuzzy lengkap $G_{2},(c)$ Contoh Graf fuzzy $G_{1} \odot G_{2}$.

Teorema 3.4. Misal diberikan graf fuzzy efektif $G_{1}$ dan graf fuzzy efektif $G$. Jika $G_{1}^{c}$ dan $G_{2}^{c}$ adalah graf fuzzy komplemen dari $G_{1}$ dan $G_{2}$ maka $G_{1}^{c} \odot G_{2}^{c}=G_{1} \odot G_{2}$.

Bukti. Misalkan diberikan dua himpunan tak kosong $V_{1}$ dan $V_{2}$. Selanjutnya diberikan dua graf fuzzy efektif $G_{1}=\left(\sigma_{1}, \mu_{1}\right)$ dan $G_{2}=\left(\sigma_{2}, \mu_{2}\right)$. Graf $G_{1}^{c}=\left(\sigma_{1}^{c}, \mu_{1}^{c}\right)$ adalah komplemen dari graf $G_{1}=\left(\sigma_{1}, \mu_{1}\right)$. Graf $G_{2}^{c}=\left(\sigma_{2}^{c}, \mu_{2}^{c}\right)$ adalah komplemen dari graf $G_{2}=\left(\sigma_{2}, \mu_{2}\right)$. Berdasarkan Definisi 3.6., $G_{1}^{c}$ memiliki derajat keanggotaan titik $\sigma_{1}^{c}(u)=\sigma_{1}(u)$ dan sisi $\mu_{1}^{c}\left(u_{i} u_{k}\right)=\min \left\{\sigma_{1}\left(u_{i}\right), \sigma_{1}\left(u_{k}\right)\right\}-\mu_{1}\left(u_{i} u_{k}\right)$. Hal ini berlaku pula pada $G_{2}^{c}$ memiliki derajat keanggotaan titik $\sigma_{2}^{c}(u)=\sigma_{2}(u)$, dan sisi $\mu_{2}^{c}\left(u_{i} u_{k}\right)=\min \left\{\sigma_{2}\left(u_{i}\right), \sigma_{2}\left(u_{k}\right)\right\}-\mu_{2}\left(u_{i} u_{k}\right)$

Karena $G_{1}=\left(\sigma_{1}, \mu_{1}\right)$ adalah graf fuzzy efektif, maka :

\section{Kasus 1.}

Jika $u_{i} u_{k} \in E_{1}$, maka $\mu_{1}\left(u_{i} u_{k}\right)=\min \left\{\sigma_{1}\left(u_{i}\right), \sigma_{1}\left(u_{k}\right)\right\}$

Hal ini berarti $\mu_{1}^{c}\left(u_{i} u_{k}\right)=\min \left\{\sigma_{1}\left(u_{i}\right), \sigma_{1}\left(u_{k}\right)\right\}-\min \left\{\sigma_{1}\left(u_{i}\right), \sigma_{1}\left(u_{k}\right)\right\}=0$

Dengan kata lain $u_{i} u_{k} \notin E_{1}^{c}$.

\section{Kasus 2.}


Jika $u_{i} u_{k} \notin E_{1}$, maka $\mu_{1}\left(u_{i} u_{k}\right)=0$.

Hal ini berarti $\mu_{1}^{c}\left(u_{i} u_{k}\right)=\min \left\{\sigma_{1}\left(u_{i}\right), \sigma_{1}\left(u_{k}\right)\right\}-0=\min \left\{\sigma_{1}\left(u_{i}\right), \sigma_{1}\left(u_{k}\right)\right\}$

Dengan kata lain $u_{i} u_{k} \in E_{1}^{c}$.

Analog untuk graf fuzzy $G_{2}$. Graf fuzzy efektif $G_{2}$, memiliki derajat keanggotaan titik $\sigma_{2}(v)$ dan derajat keanggotaan sisi $\mu_{2}\left(v_{j} v_{l}\right)=\min \left\{\sigma_{2}\left(v_{j}\right), \sigma_{2}\left(v_{l}\right)\right\}$. Graf $G_{2}^{c}$ memiliki derajat keanggotaan titik $\sigma_{2}^{c}(v)=\sigma_{2}(v)$, dan derajat keanggotaan sisi $\mu_{2}^{2}\left(v_{j} v_{l}\right)=\min \left\{\sigma_{2}\left(v_{j}\right), \sigma_{2}\left(v_{l}\right)\right\}-$ $\mu_{2}\left(v_{j} v_{l}\right)$.

Karena $G_{2}=\left(\sigma_{2}, \mu_{2}\right)$ juga graf fuzzy efektif, maka :

Kasus 1.

Jika $v_{j} v_{l} \in E_{2}$, maka $\mu_{2}\left(v_{j} v_{l}\right)=\min \left\{\sigma_{2}\left(v_{j}\right), \sigma_{2}\left(v_{l}\right)\right\}$.

Hal ini berarti $\mu_{2}^{c}\left(v_{j} v_{l}\right)=\min \left\{\sigma_{2}\left(v_{j}\right), \sigma_{2}\left(v_{l}\right)\right\}-\min \left\{\sigma_{2}\left(v_{j}\right), \sigma_{2}\left(v_{l}\right)\right\}=0$

Dengan kata lain $v_{j} v_{l} \notin E_{2}^{c}$.

\section{Kasus 2.}

Jika $v_{j} v_{l} \notin E_{2}$, maka $\mu_{2}\left(v_{j} v_{l}\right)=0$.

Hal ini berarti $\mu_{2}^{c}\left(v_{j} v_{l}\right)=\min \left\{\sigma_{2}\left(v_{j}\right), \sigma_{2}\left(v_{l}\right)\right\}-0=\min \left\{\sigma_{2}\left(v_{j}\right), \sigma_{2}\left(v_{l}\right)\right\}$

Dengan kata lain $u_{i} u_{k} \in E_{2}^{c}$.

Selanjutnya sesuai Definisi 3.3., hasil perkalian modular dari $G_{1}^{c}$ dan $G_{2}^{c}$ dinotasikan dengan $G_{1}^{c} \odot G_{2}^{c}=\left(\sigma_{1}^{c} \odot \sigma_{2}^{c}, \mu_{1}^{c} \odot \mu_{2}^{c}\right)$ adalah pasangan fungsi dengan :

$$
\begin{aligned}
\left(\sigma_{1}^{c} \odot \sigma_{2}^{c}\right)(u, v) & =\sigma_{1}^{c}(u) \wedge \sigma_{2}^{c}(v) \\
& =\sigma_{1}(u) \wedge \sigma_{1}(v) \\
& =\left(\sigma_{1} \odot \sigma_{2}\right)(u, v) .
\end{aligned}
$$

(2) $\left(\mu_{1}^{c} \odot \mu_{2}^{c}\right)\left(u_{i}, v_{j}\right)\left(u_{k}, v_{l}\right)$ yang terbagi menjadi dua kasus, yaitu :

Kasus 1. Jika $u_{i} u_{k} \notin E_{1}^{c}$ dan $v_{j} v_{l} \notin E_{2}^{c}$, maka :

$$
\begin{aligned}
\left(\mu_{1}^{c} \odot \mu_{2}^{c}\right)\left(\left(u_{i}, v_{j}\right)\left(u_{k}, v_{l}\right)\right) & =\sigma_{1}^{c}\left(u_{i}\right) \wedge \sigma_{1}^{c}\left(u_{j}\right) \wedge \sigma_{2}^{c}\left(v_{k}\right) \wedge \sigma_{2}^{c}\left(v_{l}\right) \\
& =\sigma_{1}\left(u_{i}\right) \wedge \sigma_{1}\left(u_{j}\right) \wedge \sigma_{2}\left(v_{k}\right) \wedge \sigma_{2}\left(v_{l}\right) \\
& =\left(\mu_{1} \odot \mu_{2}\right)\left(u_{i}, v_{j}\right)\left(u_{k}, v_{l}\right) .
\end{aligned}
$$

Kasus 2. Jika $u_{i} u_{k} \in E_{1}^{c}$ dan $v_{j} v_{l} \in E_{2}^{c}$, maka :

$$
\begin{aligned}
\left(\mu_{1}^{c} \odot \mu_{2}^{c}\right)\left(\left(u_{i}, v_{j}\right)\left(u_{k}, v_{l}\right)\right) & =\mu_{1}^{c}\left(u_{i} u_{k}\right) \wedge \mu_{2}^{c}\left(v_{j} v_{l}\right) \\
& =\min \left\{\sigma_{1}\left(u_{i}\right), \sigma_{1}\left(u_{k}\right)\right\} \wedge \min \left\{\sigma_{2}\left(v_{j}\right), \sigma_{2}\left(v_{l}\right)\right\} \\
& =\mu_{1}\left(u_{i}, u_{k}\right) \wedge \mu_{2}\left(v_{j}, v_{l}\right) .
\end{aligned}
$$

Akibatnya dari (1) dan (2), diperoleh bahwa $\left(\sigma_{1}^{c} \odot \sigma_{2}^{c}\right)(u, v)=\left(\sigma_{1} \odot \sigma_{2}\right)(u, v)$ dan $\left(\mu_{1}^{c} \odot\right.$ $\left.\mu_{2}^{c}\right)\left(u_{i}, v_{j}\right)\left(u_{k}, v_{l}\right)=\mu_{1}\left(u_{i} u_{k}\right) \wedge \mu\left(v_{j} v_{l}\right)$. Dengan demikian terbukti bahwa $G_{1}^{c} \odot G_{2}^{c}=G_{1} \odot G_{2}$.

Teorema 3.5. Jika $G_{1}=\left(\sigma_{1}, \mu_{1}\right)$ dan $G_{2}=\left(\sigma_{2}, \mu_{2}\right)$ adalah dua graf fuzzy, maka $G_{1} \odot G_{2} \cong G_{2} \odot G_{1}$.

Bukti. Untuk membuktikan sifat ini, diambil sembarang $(u, v) \in V_{1} \times V_{2}$, akan dibuktikan ada pemetaan bijektif $f: V_{1} \times V_{2} \rightarrow V_{2} \times V_{1}$ yang memenuhi :

(1) $\left(\sigma_{1} \odot \sigma_{2}\right)(u, v)=\left(\sigma_{2} \odot \sigma_{1}\right)(f(u, v))$,

(2) $\left(\mu_{1} \odot \mu_{2}\right)\left(\left(u_{i}, v_{j}\right)\left(u_{k}, v_{l}\right)\right)=\left(\mu_{2} \odot \mu_{1}\right)\left(f\left(u_{i}, v_{j}\right) f\left(u_{k}, v_{l}\right)\right), \forall\left(u_{i}, v_{j}\right),\left(u_{k}, v_{l}\right) \in V_{1} \times V_{2}$

Definisikan pemetaan $f: V_{1} \times V_{2} \rightarrow V_{2} \times V_{1}$ dengan $f(u, v)=(v, u)$. Berdasarkan definisi 3.3, diperoleh $G_{1} \odot G_{2}=\left(\sigma_{1} \odot \sigma_{2}, \mu_{1} \odot \mu_{2}\right)$ dengan :

$$
\begin{aligned}
\left(\sigma_{1} \odot \sigma_{2}\right)(u, v) & =\sigma_{1}(u) \wedge \sigma_{2}(v) \\
& =\sigma_{2}(v) \wedge \sigma_{1}(u) \\
& =\left(\sigma_{2} \odot \sigma_{1}\right)(v, u) \\
& =\left(\sigma_{2} \odot \sigma_{1}\right)(f(u, v))
\end{aligned}
$$

dan 
(2)

$$
\begin{aligned}
\left(\mu_{1} \odot \mu_{2}\right)\left(\left(u_{i}, v_{j}\right)\left(u_{k}, v_{l}\right)\right) & =\mu_{1}\left(u_{i} u_{k}\right) \wedge \mu_{2}\left(v_{j} v_{l}\right) \\
& =\mu_{2}\left(v_{j} v_{l}\right) \wedge \mu_{1}\left(u_{i} u_{k}\right) \\
& =\left(\mu_{2} \odot \mu_{1}\right)\left(\left(v_{j}, u_{i}\right)\left(v_{i}, u_{k}\right)\right) \\
& =\left(\mu_{2} \odot \mu_{1}\right)\left(f\left(u_{i}, v_{j}\right) f\left(u_{k}, v_{l}\right)\right), \quad \text { untuk } u_{i} u_{k} \in E_{1} \text { dan } v_{j} v_{l} \in E_{2} \\
\text { atau } & \\
\left(\mu_{1} \odot \mu_{2}\right)\left(\left(u_{i}, v_{j}\right)\left(u_{k}, v_{l}\right)\right) & =\sigma_{1}\left(u_{i}\right) \wedge \sigma_{1}\left(u_{k}\right) \wedge \sigma_{2}\left(v_{j}\right) \wedge \sigma_{2}\left(v_{l}\right) \\
& =\sigma_{2}\left(v_{j}\right) \wedge \sigma_{2}\left(v_{l}\right) \wedge \sigma_{1}\left(u_{i}\right) \wedge \sigma_{1}\left(u_{k}\right) \\
& =\left(\mu_{2} \odot \mu_{1}\right)\left(\left(v_{j}, u_{i}\right)\left(v_{i}, u_{k}\right)\right) \\
& =\left(\mu_{2} \odot \mu_{1}\right)\left(f\left(u_{i}, v_{j}\right) f\left(u_{k}, v_{l}\right)\right), \text { untuk } u_{i} u_{k} \notin E_{1} \text { dan } v_{j} v_{l} \notin E_{2}
\end{aligned}
$$

Berdasarkan bukti (1) dan (2), diperoleh $G_{1} \odot G_{2} \cong G_{2} \odot G_{1}$.

\section{Simpulan}

Dari pembahasan yang telah diberikan dapat disimpulkan sebagai berikut :

(1) Perkalian modular dari dua graf fuzzy lengkap bukan merupakan graf fuzzy lengkap.

(2) Jika $G_{1}$ dan $G_{2}$ graf fuzzy efektif, maka $G_{1}^{c} \odot G_{2}^{c} \cong G_{2} \odot G_{2}$.

(3) Graf $G_{1} \odot G_{2}$ dan $G_{2} \odot G_{1}$ saling isomorfik.

Sifat-sifat Operasi perkalian modular pada dua graf fuzzy juga dapat di kaitkan dengan operasi-operasi yang lain, sehingga perlu diselidiki hubungan operasi perkalian modular dengan operasi-operasi yang lain seperti perkalian kartesius, tensor, normal, komposisi, homomorfik, dan boxdot pada dua graf fuzzy.

\section{DAFTAR PUSTAKA}

[1] Dey A, dan Anita P. , 2013, Fuzzy Graph Coloring Technique to Classify The Accidental Zone of a Traffic Control. Annals of Pure and Applied Mathematics. Vol. 3 No.2, pp. 169-178.

[2] Dogra, S., 2015. Different Types of Product of Fuzzy Graphs. Progress in Nonlinear Dynamics and Chaos. Vol. 3 No. 1, pp. 41-56.

[3] Swaminathan S., 2012, Fuzzy Graph Applications of Job Allocation, International Journal of Engineering anf Innovative Technology, Vol. 1., Issue 2 .

[4] Mordeson, J.N dan Peng C,S. 1994. Operation on Fuzzy Graphs, Information Science 79, pp 159-170.

[5] Sunita, MS dan A. Vijaya Kumar, 2002, Complemet of Fuzzy Graph, Indian J. Pure Applied Mathematical, 33:9 hal. 14511464

[6] Zadeh L.A, Fu K.S. \& Shimura M., 1975. Fuzzy Sets and their Applications to Cognitive and Decesion Processes. Academic Press, New York. 